\title{
The Effectiveness of Acupuncture in Insomnia Patients: Meta Analysis
}

\author{
Kurnia Eka Putri'1), Bhisma Murti'), Hanung Prasetya2) \\ 1)Masters Program in Public Health, Universitas Sebelas Maret \\ ${ }^{2}$ Study Program of Acupuncture, Health Polytechnics Ministry of Health Surakarta
}

\section{ABSTRACT}

Background: Insomnia is a disease that has a negative impact on the health and well-being of the sufferer. Insomnia can occur in anyone, both men and women with various ages of vulnerability and in individuals with various socioeconomic backgrounds. This study aims to examine the effectiveness of acupuncture in insomnia patients.

Subjects and Method: Meta-analysis was performed with PICO which is presented as follows: the population in this study was insomnia patients aged 16-85. The intervention is in the form of acupuncture therapy. The comparison used was a sham/ placebo acupuncture. The outcome was insomnia. The meta-analysis study was applied to this study with electronic data sources: Clinical Key, Google Scholar, MEDLINE/ PubMed, Science Direct, Scopus. The article used is a full-text article with a randomized control trial (RCT) study design. There were 9 articles used in this study with a sample size of 649 people who were divided into two groups (372 people in the acupuncture group and 277 people in the sham / placebo acupuncture group). Articles were analyzed using the Review Manager 5.4 application. The results of this study aim to determine the Standardized Mean difference (SMD) and heterogeneity of the study sample.

Results: There is high heterogeneity between one experiment and another $\left(\mathrm{I}^{2}=94 \%\right.$; $\mathrm{p}$ $<0.001)$ so that what is used is the Random Effect Model (REM). The provision of acupuncture therapy was able to reduce the degree of insomnia with the Standardized Mean Different (SMD) of 0.98 compared to sham acupuncture $(\mathrm{SMD}=-0.98 ; 95 \% \mathrm{CI}=-1.71$ to -0.25 ; $\mathrm{p}=0.008)$.

Conclusion: The provision of acupuncture therapy was able to reduce the degree of insomnia with the Standardized Mean Different (SMD) of 0.98 compared to sham acupuncture.

Keywords: Acupuncture, Insomnia

\section{Correspondence:}

Kurnia Eka Putri. Masters Program in Public Health, Universitas Sebelas Maret, Jl. Ir. Sutami 36A, Surakarta 57126, Indonesia. Email: anggipag@gmail.com. Mobile: +628995212646.

Cite this as:

Putri KE, Murti B, Prasetya H (2021). The Effectiveness of Acupuncture in Insomnia Patients: Meta Analysis. Indones J Med. 06(01): 42-51. https://doi.org/10.26911/theijmed.2021.06.01.05.

cc (i) (2) Indonesian Journal of Medicine is licensed under a Creative Commons

EY NC SA Attribution-NonCommercial-ShareAlike 4.o International License.

\section{BACKGROUND}

Sleep is a vital aspect in human life because sleep is a basic need that must be met by every individual, just like eating and breathing. The individual's inability to fulfill the quality and quantity of sleep is certainly very influential for physical and spiritual health. The impact of insufficient fulfillment of the quality and quantity of sleep can lower the immune system, increase blood pressure, cause a decrease in concentration and brain function to affect mood (Februarianti et al, 2019).

Insomnia is a common disease in modern society, this is exacerbated by the increasing competition both in the workplace and in the social environment, both in the real social environment and the social environment in cyberspace, in line with rapid economic and social development. 
Insomnia is a disease that has a negative impact on the health and well-being of the sufferer. Insomnia can occur in anyone, both men and women with various ages of vulnerability and in individuals with various socioeconomic backgrounds (Mandıroğlu and Ozdilekcan, 2017).

Insomnia is the most common sleep disorder, about $10 \%$ to $20 \%$ of the population worldwide have problems in the form of poor sleep quality, while the prevalence of insomnia in adults and the elderly reaches $33 \%$ to $50 \%$ worldwide (Pei et al., 2019). One-third of people in the United States experience symptoms of insomnia and about $6 \%$ meet the criteria for sleep disorders (Bragg et al., 2019). The prevalence of insomnia that occurs in the elderly in Indonesia is also quite high at $67 \%$ (Februarianti et al., 2019).

Insomnia can be treated with pharmacological and non-pharmacological treatments. Pharmacological treatments have been shown to be effective in overcoming the problem of insomnia, but like the fruit of pharmacological therapy with drugs such as zaleplon and benzodiasprine can cause side effects such as memory impairment, drug resistance, drug dependence and addiction (Pei et al., 2019).

Non-pharmacological therapies such as behavioral therapy, relaxation therapy, psychotherapy and acupuncture can be a solution in overcoming insomnia. Among the many non-pharmacological options for treating insomnia, acupuncture is one of the most popular and safest therapies (Chung et al., 2016). According to Ernst and White (2001) in Yuan et al., (2016), the side effects of using acupuncture are lower than the side effects of using antidepressants. In addition, the trend of the world community which is starting to shift to minimize the use of chemicals (back to nature) is also increasing interest in acupuncture therapy.

Acupuncture has been used for thousands of years to treat a variety of ailments, including insomnia. Acupuncture is widely used in many countries on the Asian continent and as time goes by, it is increasing in Western countries (Shergis et al., 2016). Acupuncture is a therapeutic therapy by inserting a special needle (filiform needle) into acupoints that have been mapped in the human body. The insertion of needles at acupuncture points has a local effect through axons (nerve fibers), releases neuropeptides and increases blood flow in the puncture area (White, 201).

Research Yin et al., (2017) confirmed the efficacy of acupuncture in treating insomnia. This is related to the ability of acupuncture to influence the regulation of neurotransmitters and hormones in the body, acupuncture can modulate sleep, to improve sleep quality and quantity (Pei et al., 2019).

Acupuncture is effective in relieving symptoms of chronic and acute insomnia without side effects, the selection of acupoints can be adjusted according to the syndrome experienced by insomnia sufferers. In addition, acupuncture has several characteristics such as minimal side effects of physiological disorders, relatively low price, high level of safety, and simple processing by acupuncture therapists (Lin et al., 2016). In addition, acupuncture has a fast and long lasting effect, as well as satisfactory results after completing a series of therapy in cases of insomnia (Pan et al., 2017).

There have been several published systematic review articles discussing the effectiveness of acupuncture in treating insomnia. The author is interested in using meta-analysis techniques in this study to make it easier to obtain evidence-based 
Putri et al./ The Effectiveness of Acupuncture in Insomnia Patients

research results with a large sample size to determine the effectiveness of acupuncture in patients with insomnia compared to sham acupuncture (sham/ placebo acupuncture).

\section{SUBJECTS AND METHOD}

\section{A. Study Design}

This was a systematic review and metaanalysis involving various appropriate articles from electronic journal databases including: Clinical Key, Google Scholar, MEDLINE/ PubMed, Science Direct, Scopus. With keywords, among others: "acupuncture", "insomnia", "randomized controlled trial", "acupuncture and insomnia", "insomnia and randomized controlled trial", "accupuncture and randomized controlled trial", "Insomnia Severity Index", "Pittsburgh Sleep Quality Index," "acupuncture and ISI"," acupuncture and PSQI.

\section{B. Inclusion Criteria}

1. The article used is a full paper article

2. The article is appropriately titled and deals with the effectiveness of acupuncture on insomnia

3. Articles published in English and / or Indonesian

4. The article uses the Randomized Controlled Trial (RCT) study design

5. Include the results of the study in the form of the number of respondents, the mean value and the value of standard deviation (SD)

6 . The research subjects were adults aged 18 - 85 years

7. Intervention on research subjects in the form of acupuncture

8. The intervention in the control group was sham / placebo acupuncture

\section{Exclusion Criteria}

1) Not a full paper article

2) Articles that use quasi-experimental study design, protocol study, plot study, cohort, case control and cross-sectional study.

3) Articles use languages other than English and Indonesian

4) The research subjects were animals

D. Operational Definition of Variable Acupuncture is an intervention by inserting a special needle (filiform needle) into acupoints that have been mapped in the human body.

Sham/ Palcebo Acupuncture is an intervention by inserting real acupuncture needles but inserted superficially so that it does not hit the acupuncture points or uses different acupuncture points, where these points have different functions and uses.

Insomnia is a sleep disorder in the form of difficulty starting to sleep, difficulty maintaining sleep as expected, waking up at night and waking up too early in the morning

\section{E. Instruments}

Published articles obtained from various appropriate electronic journal databases include: Clinical Key, Google Scholar, MEDLINE/ PubMed, Science Direct, Scopus. This research was conducted for 30 days (October 14, 2020 to November 14, 2020) by searching and selecting the results of research and on various races, ethnicities and locations in the world.

\section{F. Data Analysis}

This research was conducted using secondary data in the form of data from the results of previous research and data processing was carried out using the Review Manager (RevMan 5.4).

\section{RESULTS}

The article selection process is carried out using the Mendeley desktop application. In the initial process of searching for articles, 1668 articles were obtained.

After the checking process was carried out, the same 812 articles were found, so 
Putri et al./ The Effectiveness of Acupuncture in Insomnia Patients

that the duplicate articles were deleted. Then, obtained 856 articles that have been filtered. Of the 856 articles, 803 were excluded because they did not meet the inclusion criteria. The 53 existing articles were screened again and there were 44 articles that were not suitable because they did not meet the inclusion criteria.

There are 9 articles which are the final results of article selection that are included in the systematic review and meta-analysis process.

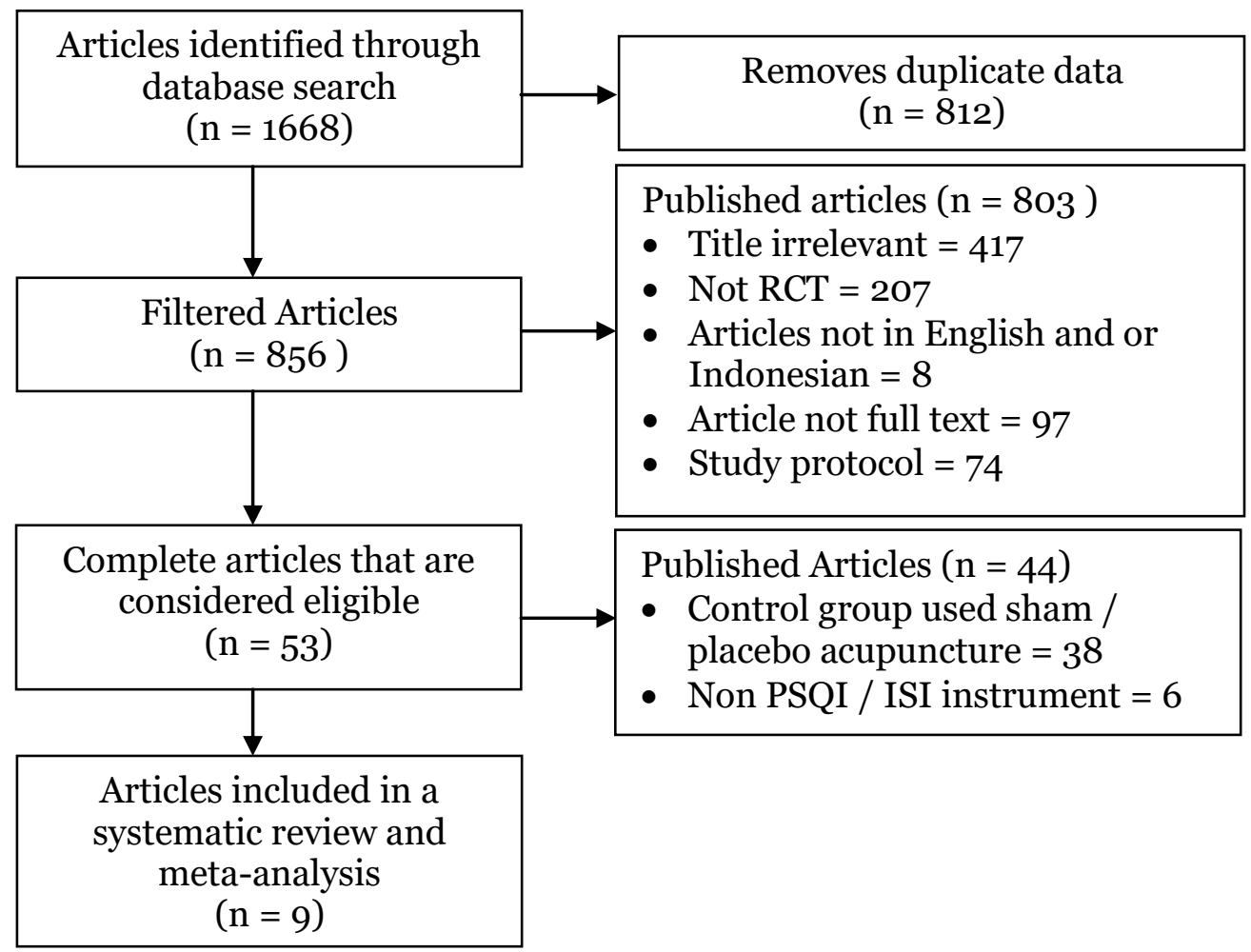

Figure 1. Flow chart of the article review process

There were 9 randomized controlled trial (RCT) studies that were used as research sources for systematic studies and meta-analyzes of the effectiveness of acupuncture in insomnia sufferers in this study. An overview of the PICO (Population, Intervention, Comparison, Outcome) of 9 articles used in the systematic study and meta-analysis in this study can be seen in table 1. 
Table 1. PICO (Population, Intervention, Comparison and Outcome) of each study

\begin{tabular}{|c|c|c|c|c|}
\hline Authors & P (Population) & I (Intervention) & $\begin{array}{c}\mathrm{C} \\
\text { (Comparison) }\end{array}$ & O (Outcome) \\
\hline $\begin{array}{l}\text { Lee et al } \\
(2009)\end{array}$ & $\begin{array}{l}\text { Research subjects with insomnia based } \\
\text { on the value of the Insomnia Severity } \\
\text { Index (ISI). ( } n=150)\end{array}$ & $\begin{array}{l}\text { Acupuncture on point: Shenmen ( Ht 7) dan } \\
\text { Nei Guan (Pc 6) }\end{array}$ & $\begin{array}{l}\text { Acupuncture } \\
\text { sham }\end{array}$ & $\begin{array}{l}\text { Insomnia Severity Index } \\
\text { (ISI) Value }\end{array}$ \\
\hline $\begin{array}{l}\text { Yeung et al } \\
(2009)\end{array}$ & $\begin{array}{l}\text { Study subjects with insomnia who had } \\
\text { been diagnosed by a doctor based on } \\
\text { the DSM-IV with the Insomnia Severity } \\
\text { Index (ISI) value. }(\mathrm{n}=6 \mathrm{o})\end{array}$ & $\begin{array}{l}\text { Acupuncture on point: Yintang (EX-HN3), } \\
\text { Baihui (GV2O), bilateral Ear Shenmen, } \\
\text { Sishencong (EX-HN1), dan Anmian (EX) }\end{array}$ & $\begin{array}{l}\text { Acupuncture } \\
\text { placebo }\end{array}$ & $\begin{array}{l}\text { Value of the Insomnia } \\
\text { Severity Index (ISI) and } \\
\text { the Pittsburgh Sleep } \\
\text { Quality Index (PSQI) }\end{array}$ \\
\hline $\begin{array}{l}\text { Yeung et al } \\
\text { (2011) }\end{array}$ & $\begin{array}{l}\text { Study subjects with insomnia who had } \\
\text { already been diagnosed by a doctor } \\
\text { based on DSM-IV. }(\mathrm{n}=78)\end{array}$ & $\begin{array}{l}\text { Acupuncture on point: Yintang (EX-HN3), } \\
\text { Baihui (GV2O), bilateral Ear Shenmen, } \\
\text { Sishencong (EX-HN1), dan Anmian (EX) }\end{array}$ & $\begin{array}{l}\text { Acupuncture } \\
\text { placebo }\end{array}$ & $\begin{array}{l}\text { Value of the Insomnia } \\
\text { Severity Index (ISI) and } \\
\text { the Pittsburgh Sleep } \\
\text { Quality Index (PSQI) }\end{array}$ \\
\hline $\begin{array}{l}\text { Dias et al } \\
(2012)\end{array}$ & $\begin{array}{l}\text { Study subjects with insomnia with } \\
\text { moderate }(28-30) \text { or severe }(>30) \text { sleep } \\
\text { quality criteria. }(n=25)\end{array}$ & $\begin{array}{l}\text { Acupuncture on point: } \\
\text { ST } 36, \text { PC } 6 \text {, GB 14, CV } 20 \text { dan Sishencong }\end{array}$ & $\begin{array}{l}\text { There is no } \\
\text { intervention }\end{array}$ & $\begin{array}{l}\text { Pittsburgh Sleep Quality } \\
\text { Index (PSQI) values }\end{array}$ \\
\hline $\begin{array}{l}\text { Chung et al } \\
\text { (2016) }\end{array}$ & $\begin{array}{l}\text { Research subjects with insomnia based } \\
\text { on the value of the Insomnia Severity } \\
\text { Index (ISI). }(\mathrm{n}=15 \mathrm{O})\end{array}$ & $\begin{array}{l}\text { Acupuncture on point : Shenmen, } \\
\text { Sishencong (EX-HN1), Anmian (EX), } \\
\text { Neiguan (PC6), Shenmen (HT7), Sanyinjiao } \\
\text { (SP6), Yintang (EX-HN3) and Baihui } \\
\text { (GV2O). }\end{array}$ & $\begin{array}{l}\text { Palcebo } \\
\text { acupuncture }\end{array}$ & $\begin{array}{l}\text { Value of the Insomnia } \\
\text { Severity Index (ISI) and } \\
\text { the Pittsburgh Sleep } \\
\text { Quality Index (PSQI) }\end{array}$ \\
\hline $\begin{array}{l}\text { Fu et al } \\
(2017)\end{array}$ & $\begin{array}{l}\text { Study subjects with insomnia who had } \\
\text { already been diagnosed by a doctor } \\
\text { based on the DSM-V. (n=72) }\end{array}$ & $\begin{array}{l}\text { Acupuncture on point: Shensu (BL 23), } \\
\text { Ganshu (BL 11), Qimen (LV 14) dan } \\
\text { Jingmen (GB 25) }\end{array}$ & $\begin{array}{l}\text { Acupuncture } \\
\text { placebo }\end{array}$ & $\begin{array}{l}\text { Value of the Insomnia } \\
\text { Severity Index (ISI) and } \\
\text { the Pittsburgh Sleep } \\
\text { Quality Index (PSQI) }\end{array}$ \\
\hline $\begin{array}{l}\text { Yin et al } \\
(2017)\end{array}$ & $\begin{array}{l}\text { Study subjects with insomnia who have } \\
\text { been diagnosed by a doctor based on } \\
\text { the DSM-V, Insomnia Severity Index } \\
\text { (ISI), sleep efficiency (SE) less than } \\
85 \% .(n=72)\end{array}$ & $\begin{array}{l}\text { Acupuncture on point: Baihui (GV 20), } \\
\text { Shenting (GV 24), Yintang (GV 29), Anmia } \\
\text { (EX HN 22), Shenmen (HT 7), Sanyinjiau } \\
\text { (SP 6) }\end{array}$ & $\begin{array}{l}\text { Acupuncture } \\
\text { sham }\end{array}$ & $\begin{array}{l}\text { Insomnia Severity Index } \\
\text { (ISI) Value }\end{array}$ \\
\hline $\begin{array}{l}\text { Chung et al } \\
(2019)\end{array}$ & $\begin{array}{l}\text { Research subjects with insomnia based } \\
\text { on PSQI score }>7 \text {, SAS score } \geq 50 \text {, SDS } \\
\text { score } \geq 50 \text {. }(n=96)\end{array}$ & $\begin{array}{l}\text { Acupuncture on point: Anmian (EX-HN22), } \\
\text { Neiguan (PC6), Shenmen (HT7), Hegu } \\
\text { (LI4), Zusanli (ST36), Zhaohai (KI6), }\end{array}$ & $\begin{array}{l}\text { Acupuncture } \\
\text { placebo }\end{array}$ & $\begin{array}{l}\text { Pittsburgh Sleep Quality } \\
\text { Index (PSQI) values }\end{array}$ \\
\hline
\end{tabular}




\begin{tabular}{llll}
\hline \multicolumn{1}{c}{ Authors } & \multicolumn{1}{c}{ P (Population) } & \multicolumn{1}{c}{ I (Intervention) } & \multicolumn{1}{c}{ C (Outcome) } \\
\hline (Comparison)
\end{tabular}

Table 3. Assessment of Research Quality (Critical Appraisal)

\begin{tabular}{|c|c|c|c|c|c|c|c|c|c|}
\hline \multirow[b]{2}{*}{ Item } & \multicolumn{9}{|c|}{ Publication } \\
\hline & $\begin{array}{c}\text { Lee et al } \\
(2009)\end{array}$ & $\begin{array}{l}\text { Yeung et } \\
\text { al (2009) }\end{array}$ & $\begin{array}{l}\text { Yeung et } \\
\text { al (2011) }\end{array}$ & $\begin{array}{l}\text { Dias et al } \\
\quad(2012)\end{array}$ & $\begin{array}{l}\text { Chung et } \\
\text { al (2016) }\end{array}$ & $\begin{array}{l}\text { Fu et al } \\
(2017)\end{array}$ & $\begin{array}{c}\text { Yin et al } \\
(2017)\end{array}$ & $\begin{array}{l}\text { Chung et } \\
\text { al (2019) }\end{array}$ & $\begin{array}{l}\text { Zhang et } \\
\text { al (2020) }\end{array}$ \\
\hline $\begin{array}{l}\text { Relevance of goals and } \\
\text { problems }\end{array}$ & 1 & 1 & 1 & 1 & 1 & 1 & 1 & 1 & 1 \\
\hline $\begin{array}{l}\text { Relevance of methods and } \\
\text { problems }\end{array}$ & 1 & 1 & 1 & 1 & 1 & 1 & 1 & 1 & 1 \\
\hline Sample adequacy & 1 & 1 & 1 & 1 & 1 & 1 & 1 & 1 & 1 \\
\hline Sample validity & 1 & 1 & 1 & 1 & 1 & 1 & 1 & 1 & 1 \\
\hline $\begin{array}{l}\text { Cases and controls were } \\
\text { comparable }\end{array}$ & 1 & 1 & 1 & 1 & 1 & 1 & 1 & 1 & 1 \\
\hline There is no bias & $\mathrm{O}$ & 1 & 1 & 1 & 1 & 1 & 1 & 1 & 1 \\
\hline Information data tracking & 1 & 1 & 1 & 1 & 1 & 1 & 1 & 1 & 1 \\
\hline $\begin{array}{l}\text { Analysis of relevant and } \\
\text { valid data }\end{array}$ & 1 & 1 & 1 & 1 & 1 & 1 & 1 & 1 & 1 \\
\hline Relevance Effect Size & 1 & 1 & 1 & 1 & 1 & 1 & 1 & 1 & 1 \\
\hline 95\% CI reporting & 1 & 1 & 1 & 1 & 1 & 1 & 1 & 1 & 1 \\
\hline $\begin{array}{l}\text { Confounding factors } \\
\text { reported }\end{array}$ & 1 & 1 & 1 & 1 & 1 & 1 & 1 & 1 & 1 \\
\hline Results can be applied & 1 & 1 & 1 & 1 & 1 & 1 & 1 & 1 & 1 \\
\hline Total & 11 & 12 & 12 & 12 & 12 & 12 & 12 & 12 & 12 \\
\hline
\end{tabular}

Total

Yes $=1$

$\mathrm{No}=\mathrm{O}$ 
Putri et al./ The Effectiveness of Acupuncture in Insomnia Patients

Interpretation of the results of the meta-analysis of the 9 primary research articles in this study can be seen in the forest plot image (Figure 2). Based on the results of the analysis using RevMan 5.4 software, it is known that there is high heterogeneity between one experiment and another $\left(I^{2}=94 \% ; p<0.001\right)$ so that the
Random Effect Model (REM) is used. The provision of acupuncture therapy was able to reduce the degree of insomnia with the Standardized Mean Different (SMD) of o.98 compared to sham acupuncture $(\mathrm{SMD}=-0.98 ; 95 \% \mathrm{CI}=-1.71$ to $-0.25 ; \mathrm{p}=$ 0.008).

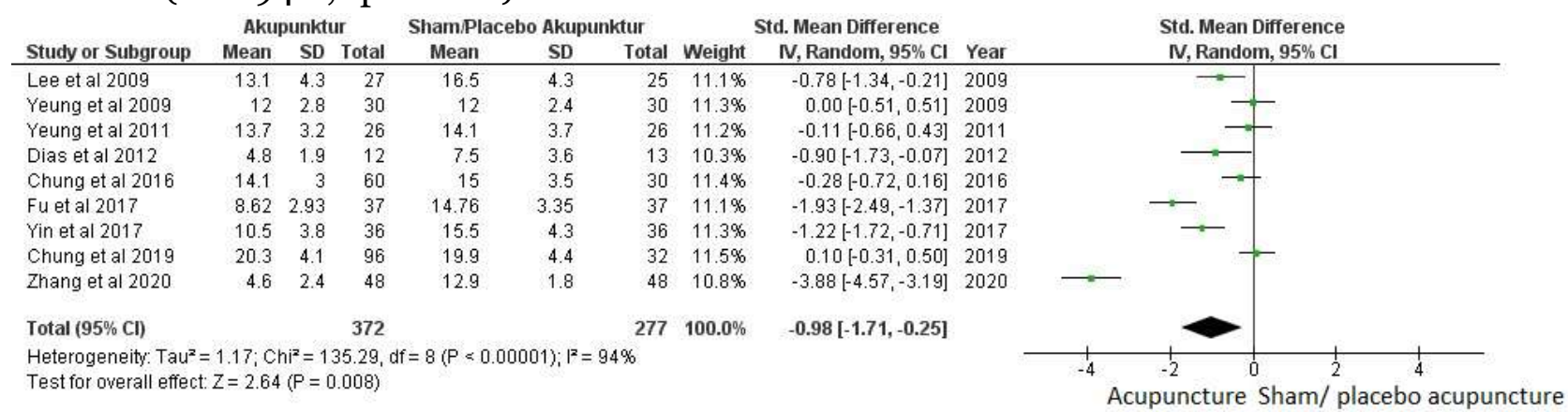

Figure 2. Forest plot

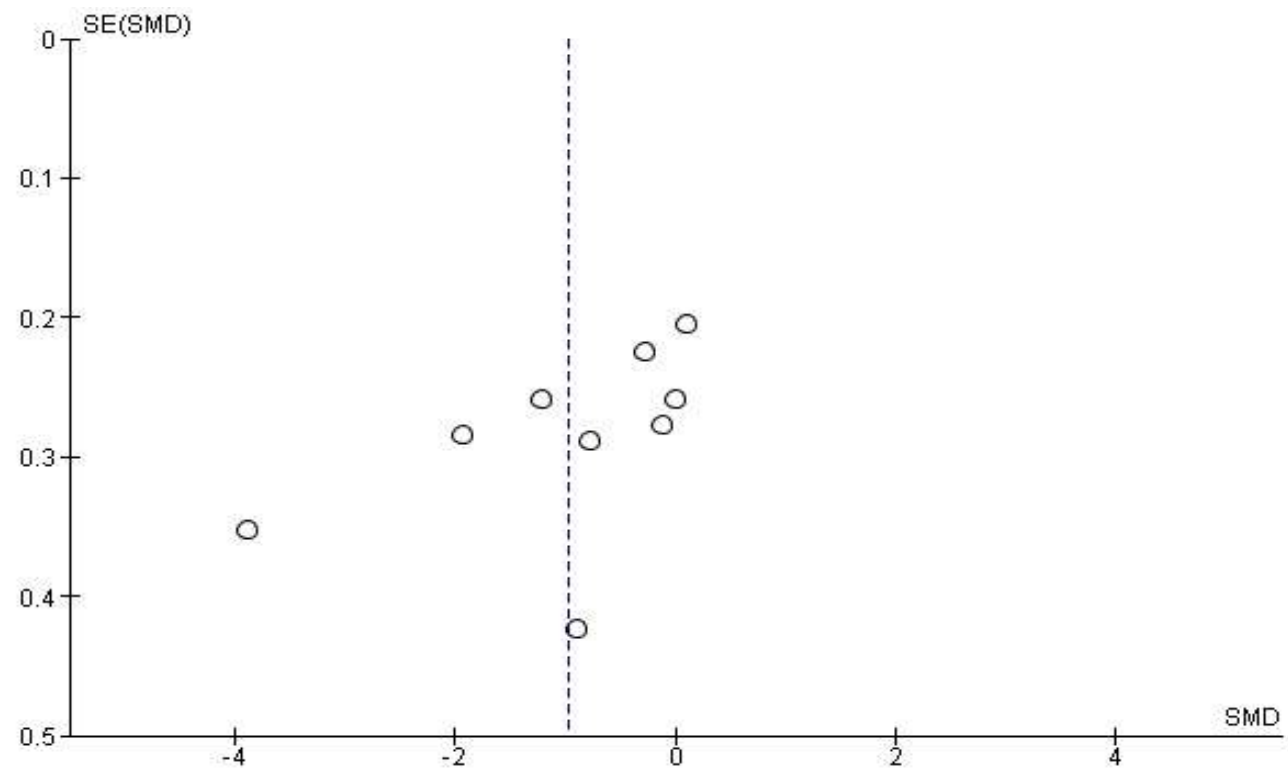

Figure 3. Funnel plot

A funnel plot is a plot that depicts the effect size of each study on the estimate of its accuracy which is usually the standard error. The interpretation of the funnel plot results indicated that there was no publication bias. This is indicated by: 1 . The shape of the plot is symmetrical on the right and left side, 2. The distance between the plots is balanced, 3. The SE value <0.5. An overview of the funnel plot in this study can be seen in the funnel plot image (Figure 3). The funnel plot image in this study shows that there is publication bias. This is indicated by asymmetry of the right and left sides of the plot. On the right side there are 5 circles and on the left there are 3 circles. However, the left side of the funnel plot in this study has a Standard Error (SE> 0.2) 
Putri et al./ The Effectiveness of Acupuncture in Insomnia Patients

and the right side of the funnel plot in this study has a Standard Error (SE <0.5).

\section{DISCUSSION}

Acupuncture is a therapeutic therapy by inserting a special needle (filiform needle) into acupoints that have been mapped in the human body. There are 361 acupuncture points that have entered into the international nomenclature, 361 points are divided into 14 meredian (acupuncture channels) (Godson and Wardle, 2019).

Insomnia is a sleep disorder that is most recognized by the public. Clinical features Insomnia is characterized by poor sleep quality that is self-reported by the sufferer, or insufficient sleep even though there is adequate sleep opportunity supported by an environment conducive to sleep, and accompanied by daytime dysfunction. Left untreated, insomnia is closely associated with a number of adverse physical and emotional health problems (Grima et al., 2019).

This meta-analysis study took the topic of the effectiveness of acupuncture in insomnia sufferers, where the independent variable in this study was acupuncture and the dependent variable in this study was insomnia. Confounding factors are things that cannot be avoided in a study, but can be controlled.

Confounding factors affect the relationship or effect of exposure to the disease incidence estimated (estimated) by the study is not the same as the relationship or effect that actually occurs in the target population, aka the study results are invalid (not true) (Murti, 2018).

This systematic review study and meta-analysis used studies that controlled for confounding factors. This can be seen from the inclusion and exclusion requirements required in this study, so that it can control the confounding factors that can make this study invalid. There are 9 articles that have passed the inclusion and exclusion requirements of a number of primary studies that were included in this systematic review and meta-analysis. Then the number of respondents, the mean and standard deviation (SD) values were combined and processed using the RevMan 5.4 application. The mean and standard deviation (SD) values were obtained from the insomnia measurement scale, namely the Insomnia Severity Index (ISI) and the Pittsburgh Sleep Quality Index (PSQI).

Insomnia Severity Index (ISI) has become one of the most commonly used assessment tools to measure the severity of insomnia. This tool was developed based on the Diagnostic and Statistical Manual of Mental Disorders, fourth edition. The Insomnia Severity Index (ISI) is a sensitive screening and outcome measure of insomnia treatment. There are threshold values established to identify individuals with different levels of insomnia. The Insomnia Severity Index (ISI) has a 7-item self-report questionnaire that assesses the nature, severity and impact of insomnia (Wong et al., 2017). Meanwhile, the Pittsburgh Sleep Quality Index (PSQI) is used to provide a standard that is easy for clinicians and patients to use to measure sleep quality. The PSQI questionnaire measures sleep quality in 1 month intervals and consists of 19 questions that measure 7 components of the assessment, namely subjective sleep quality, sleep latency, sleep duration, effective sleep duration in bed ( habitual sleep efficiency), sleep disturbance, use of sleep medication, and concentration problems during the day (daytime dysfunction).

The results of data processing carried out using the RevMan 5.4 application in this study with 9 articles from Brazil, China, Hong Kong and Korea show that the provision of acupuncture therapy is able to 
reduce the degree of insomnia with Standardized Mean Different (SMD) of 0.98 compared to fake acupuncture (sham/ placebo acupuncture), and this was statistically significant with a significance value $(\mathrm{SMD}=-0.98 ; 95 \% \mathrm{CI}=-1.71$ to $-0.25 ; \mathrm{p}=$ 0.008).

This is in line with a previous metaanalysis study by Dong et al., (2017) which stated that acupuncture treatment made significant improvements in PSQI scores in insomnia sufferers $(\mathrm{MD}=-2.37,95 \% \mathrm{CI}=-$ 3.52 to - 1.21) compared to Western medicine. The results of this systematic review and meta-analysis suggest that acupuncture can be an alternative therapy for the treatment of depression-related insomnia.

In addition, systematic review research and other meta-analyzes conducted by Shergis et al., (2016) also stated that acupuncture is superior to Cognitive Behavior Therapy (CBT) in terms of improving PSQI scores $(\mathrm{MD}=-0.79,95 \% \mathrm{CI}=-1.38$ to -0.19 , $\left.\mathrm{I}^{2}=49 \%\right)$. In addition, this study also showed that acupuncture was also more effective than pharmacotherapy (MD -2.76, $95 \% \mathrm{CI}=-3.67$ to -1.85 , I2 = 94\%).

\section{AUTHOR CONTRIBUTION}

Kurnia Eka Putri as the main researcher is as a research implementer, research data collector, person who formulates research articles, and data processor. Bhisma Murti played a role in formulating a frame of mind and analyzing research data. Hanung Prasetya played a role in the background and discussion of the research.

\section{CONFLICT OF INTEREST}

There is no conflict of interest in this study.

\section{FUNDING AND SPONSORSHIP}

The source of funds in this research is from the Ministry of Health of the Republic of Indonesia

\section{ACKNOWLEDGEMENT}

The researchers expressed gratitude to the Ministry of Health of the Republic of Indonesia, Poltekkes Kemenkes Surakarta, Sebelas Maret University Library and Electronic databases: Clinical Key, Google Scholar, MEDLINE/ PubMed, Science Direct, Scopus.

\section{REFERENCE}

Bragg SS, Benich JJ, Christian N, Visserman J, Freedy J (2019). Updates in insomnia diagnosis and treatment. Int J Psychiatry Med. 54(4-5): 275-289. https://doi.org/10.1177/00912174198 60716.

Chung KF, Yeung WF, Leung FCY, Zhang SP (2016). Traditional Chinese medicine diagnosis and response to acupuncture for insomnia: An analysis of two randomized placebo-controlled trials. Eur J Integr Med. 8(5): 797801. https://doi.org/10.1016/j.eujim.2016.06.021.

Dong B, Chen Z, Yin X, Li D, Ma J, Yin P, Cao Y, Lao L, Xu S (2017). The efficacy of acupuncture for treating depression-related insomnia compared with a control group: A systematic review and meta-analysis. Biomed Res Int. 2017: 9614810. doi: 10.1155/2017/9614810.

Februanti S, Hartono D, Cahyati A (2019). Penyakit fisik dan lingkungan terhadap insomnia bagi lanjut usia. Quality. Jurnal Kesehatan, 13(1): 1-4. doi: 10.36082/qjk.v13i1.51.

Godson DR, Wardle JL (2019). Accuracy and precision in acupuncture point location: A critical systematic review. J Acupunct Meridian Stud. 12(2): 5266. doi: 10.1016/j.jams.2018.10.009.

Grima NA, Bei B, Mansfield D (2019). Insomnia theory and assessment. 
Putri et al./ The Effectiveness of Acupuncture in Insomnia Patients

Aust J Gen Pract. 48(4): 193-197. doi: 10.31128/AJGP-12-18-4780.

Lin YF, Liu ZD, Ma W, Shen WD (2016). Hazards of insomnia and the effects of acupuncture treatment on insomnia. $\mathrm{J}$ Integr Med. 14(3): 174-186. doi: 10.1016/S2095-4964(16)60248-0.

Mandiroğlu S, Ozdilekcan C (2017). Impact of acupuncture on chronic insomnia: A report of two cases with polysomnographic evaluation. $\mathrm{J}$ Acupunct Meridian Stud. 10(2): 135-138. doi: 10.1016/j.jams.2016.09.018.

Murti B (2018). Prinsip dan Metode Riset Epidemiologi (Edisi V). Surakarta: Bintang Fajar Offset

Pan Y, Luo J, Zhang H (2017). Study on the effect of acupuncture at Sìshéncōng (四神聪 EX-HN 1) and Băihuì (百会 GV 20) on the serum amino acids neurotransmitters of insomnia patients. World J Tradit Chin Med 27(1): 23-27. doi: 10.1016/s1003-5257(17)30095-8.

Pei, Peng R, Gu Y, Zhou X, Ruan J (2019). Research trends of acupuncture therapy on insomnia in two decades (from 1999 to 2018):a bibliometric analysis. BMC Complement Altern Med 19(1): 1-9. doi: 10.1186/s12906019-2606-5.
Shergis JL, Ni X, Jackson ML, Zhang AL, Guo X, Li Y, Xue CC (2016). A systematic review of acupuncture for sleep quality in people with insomnia. Complement Ther Med 26: 11-20. doi: 10.1016/j.ctim.2016.02.007.

White A (2017) Western medical acupuncture: A definition. Acupuncture in Medicine 27(1): 33-35doi: 10.1136/aim.2008.000372.

Wong ML, Lau KNT, Espie CA, Luik AI, Kyle SD, Lau EYY (2017). Psychometric properties of the Sleep Condition Indicator and Insomnia Severity Index in the evaluation of insomnia disorder. Sleep Medicine 33: 76-81. doi: 10.1016/j.sleep.2016.05.019.

Yin X, Gou M, Xu J, Dong B, Yin P, Masquelin F, Xu S (2017). Efficacy and safety of acupuncture treatment on primary insomnia: a randomized controlled trial. Sleep Medicine. 37: 193200. doi: 10.1016/j.sleep.2017.02.012.

Yuan QL, Wang P, Liu L, Sun F, Cai YS, Wu WT, Ye ML, Ma JT, Xu BB, Zhang YG (2016). Acupuncture for musculoskeletal pain: A meta-analysis and metaregression of sham-controlled randomized clinical trials. Sci Rep. 6: 1-24. doi: 10.1038/srep30675. 